\title{
Environmental construction safety on loess soils in the coastal zone of reservoirs
}

\author{
Margarita Baranova ${ }^{1}$, Andrey Maltsev ${ }^{1}$, and Darya Vasilyeva $^{1, *}$ \\ ${ }^{1}$ Samara State Technical University, Institute of Architecture and Civil Engineering, 194 \\ Molodogvardeyskaya St., 443001,Samara, Russia
}

\begin{abstract}
The Volga region territory is a region with very high environmental stress because there are various industries, agriculture, and a large number of major cities, high population density. The probability of natural and man-made disasters is increasing in recent years. They cause significant damage to the economy and the environment. Also, they are accompanied by the destruction of human settlements and human victims. A large number of accidents are related to the soil properties. That is why the peculiarities of its geotechnical properties that are different from other soil types are important. In the European part of Russia, the loess soils are widely spread in the mid-channel of the Volga River, which currently represents a cascade of reservoirs created over 50 years ago. Within the Samara region, there are two large lowland reservoirs on the Volga (Kuybyshev and Saratov), which have a significant impact on the surrounding area. The paper describes the specific geotechnical properties of loess soils, their characteristic geological processes, material composition and microstructure features, as well as their changes during flooding. The effects of flooding on the loess soils in urban areas have been studied. The following results were obtained: identified the range of variation of physico-mechanical properties of soils and it is shown that as a result of years of flooding have changed significantly the properties of collapsible soils and their classification (category from solid to lowplasticity).
\end{abstract}

\section{Introduction}

Despite the vast area of the land (1709.8 million ha, which is 1/9 of the total land area of the Earth) Russia is a highly urbanized country where 109 million people live in cities and urban-type villages or $74 \%$ of the total population. At the same time, there is a trend of urban population growth due to economic, political, social and other reasons. About $15 \%$ of the Russian territory relates to the areas, the ecological condition of which is unsatisfactory, the area is more than the Western and Central Europe combined [1].

The Volga region refers to the regions with very high environmental stress as characterized by a highly developed industry and agriculture. Natural and technogenic disasters pose a serious threat to environmental safety, frequency, scale and destructiveness

* Corresponding author: vasilievadi@mail.ru 
of which have increased significantly in recent years. They cause great damage to the economy and the environment and are often accompanied by the destruction of human settlements and human victims.

As a rule, emergency and catastrophic situations occur naturally and can't be prevented. However, the scale of damage they cause often depends on the timeliness and accuracy of their predictions, precautionary protection measures, as well as taking into account the likelihood and intensity of their manifestation in the daily business activities.

Catastrophic events can occur during the initiation of technogenic accidents by natural factors and also the anthropogenic activities may lead to the initiation of natural disasters. As a rule, catastrophic situations cause the greatest damage in urban areas. It happens because of the high population density and the presence of plants and factories in the cities. A large number of natural and technogenic disasters are related to the properties of soil under the buildings $[2,3]$.

Loess soil is widely spread on the land surface, occupying nearly $17 \%$ of the territory of Russia. Large areas are covered by loess in Siberia, Central Asia, Kazakhstan, they are often found in Belarus, Ukraine, but the largest area covered by these rocks is located in China. As is known, this soil is sufficiently stable base in a state of natural moisture, but it has a unique feature - subsidence, which is manifested in the soil soaking. The loess properties must be considered when building industrial and civil objects on it, especially in the areas of big cities where there is an increase in density and number of storeys in a building.

When building reservoirs a change in groundwater level in the area of influence takes place with a radius up to a few kilometers. It is particularly evident when creating reservoirs on the major lowland rivers. According to the results of many years engineering and geological studies in Samara, it was found that there is a change in the loess soil properties under the increase of the groundwater level in the large reservoir areas located on the Volga river [4].

The study of loess has more than a hundred years, and during this time it has been offered a lot of (over 20) different hypotheses concerning their formation. The most commonly accepted hypothesis explain the emergence of loess by eolian (wind) or waterway. The eolian hypothesis was first proposed by F.Richthofen (1877) as a result of studying the loess in China. He included the loess with the eolian (wind) deposits, but he did not think that the wind was the only factor in the formation of loess material. F. Richthofen concluded that loess material (silt) was transferred and deposited by wind and rainwater in internal drainage basins and held there by steppe vegetation.

The eolian hypothesis was supported by scientists from Russia and other countries who supplemented and developed it. P.A. Tutkovsky (1899) connected the loess formation with the deflation of glacial deposits by the wind, which transferred the dust far away from the ice sheet. The US researchers F. Leverett (1899), T. Chamberlin and others (1909) explained the dust strata formation by the river and water glacial deposits deflation of the nearby river valleys. V.A. Obruchev (1904) linked the solid loess cover formation in high relief elements to the accumulation of dust brought from the remote areas (the so-called exotic dust). Eolian hypothesis explains well the cover occurrence of loess on large areas, and it is confirmed by the facts of rapid accumulation of silty sediments with a large capacity in arid regions after dust storms $[5,6]$.

Aqueous hypothesis hypotheses explain only the silt deposits accumulation process, but they can't answer how dust sediments became loess with its characteristics. The supporters of this hypothesis were the following scientists: V.V. Dokuchaev (1892), A.P. Pavlov (1898), Yu. Skvortsov (1948) and others who linked the strata formation of dust deposits to water denudation and subsequent redeposition of sloping rocks, transfer and accumulation 
of mineral material in the river valleys and lakes, as well as the transfer and accumulation of loess sediments of water and glacial streams. The soil and eluvial hypotheses explain the transformation of silty deposits into loess, regardless the manner of their accumulation, as a result of deflation and soil formation $[7,8]$.

\section{Materials and methods}

We studied the loess soil properties which depend on the material and granulometric composition, as well as the structural and textural structure.

Material composition is determined by macroscopic description and microscopic study. The macroscopic description includes color, dispersion structure, the texture when observing the bedding (slab or plate parting while drying) and reservoir formations (lumpy or angular pieces). The microscopic study allows us to approximately determine the mineral composition of the dominant components $[9,10]$.

The mineral composition of the loess soil often doesn't have a wide diversity. The predominant mass $(55-80 \%)$ is presented by silica in the form of quartz or chalcedony; the cementing part consists of clay mineral aggregates in the form of hydromica and montmorillonite, kaolinite (15-30\%); the admixture is represented by water-soluble minerals, carbonates in large quantity, and there also may be gypsum, anhydrite, halite is more seldom $(5-15 \%)$ [11, 12].

According to the granulometric composition and the plasticity number, the loess soils are referred to the silty sandy clay and loam soil. The loess soil humidity in its natural state does not usually exceed $0,08-0,16$, the degree of humidity is less than 0.5 , porosity - 40 $50 \%$. They are characterized by a lot of macropores in the form of tubular ducts $0.1-4 \mathrm{~mm}$ in diameter, predominantly with a vertical arrangement.

When the natural moisture, the loess soils have the strength because of grouting connections and are able to keep the vertical slopes of $10 \mathrm{~m}$ height and even more. The fewer hydration results in the dissolution of the grouting connections, thus their macroporous structure is destroyed.

When soaking the loess soil there may be a significant reduction of its volume, resulting in an uneven subsidence of the ground surface and buildings destruction constructed thereon. Subsidence is a rapidly growing settlement of the earth's surface caused by abrupt changes in soil structure when its moisture increases. At the same time, there is a reduction of soil strength; significant and fast-growing seal distortion occurs. That is why the loess soils are called subsiding $[6,13]$.

Furthermore, the suffusion phenomenon is typical of loess soils, that is, the mechanical removal of particles from moving groundwater. On the banks of the Kuibyshev Reservoir (in the Spassky district of the Republic of Tatarstan) the suffusion tunnels with a diameter of about $1 \mathrm{~m}$ were found in the loess strata when examining the coast in 2016 (Fig. 1) 


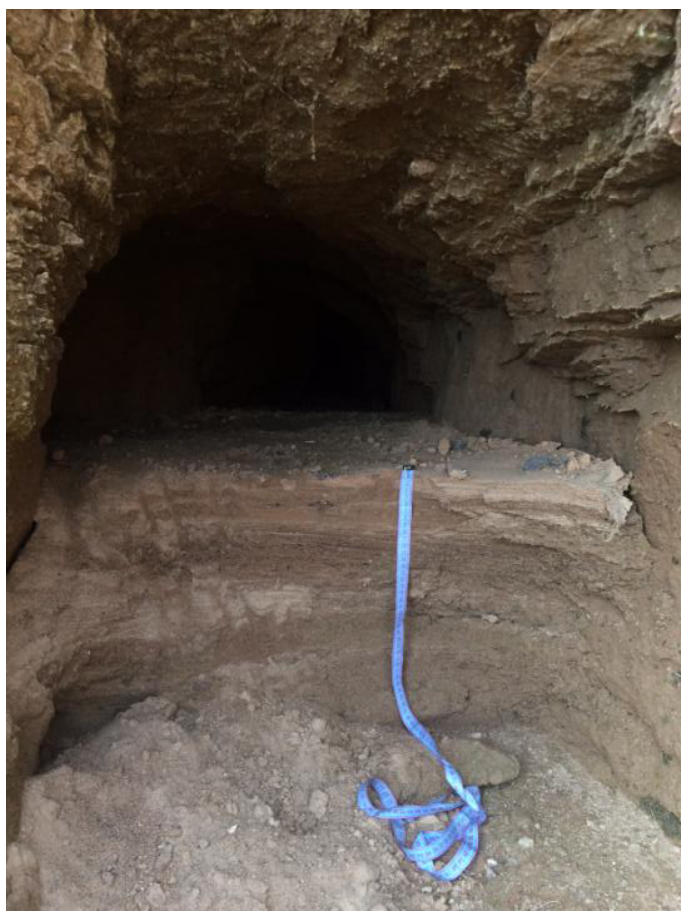

Fig. 1. The suffusion tunnel in the loess strata on the shore of the reservoir (the author's photo).

\section{Results}

The loess soils are widespread in Samara, which is located on the watershed, plateau near water-divide and terraces above the floodplain of the Volga and Samara rivers. The territory of the city has an area of 54.138 million hectares and it stretches along the Volga River on a $64 \mathrm{~km}$ strip up to $20 \mathrm{~km}$ wide. The geographical coordinates of the city are $53^{\circ}$ 14 'N, $50^{\circ} 14^{\prime}$ E. The city was founded in 1586 at the confluence of the Samara River to the Volga River. [4]

The lowest forms of relief in the city are the floodplain terraces of the Volga and Samara rivers. When the Saratov Reservoir was built (1967-1868), the most part of the low floodplain was flooded and there was a gradual raising of the groundwater level. The Saratov Reservoir at the highest head water level has a volume of $12.9 \mathrm{~km}^{3}$, the watersurface area of $181 \mathrm{~km}^{2}$, the catchment area of $1280000 \mathrm{~km}^{2}$. The width of the reservoir varies from 1 to $12 \mathrm{~km}$, the depth - from 3 to $26 \mathrm{~m}$, the length of the main fairway is 336 $\mathrm{km}$. The water level in Samara has risen by $5.5 \mathrm{~m}$ compared to low water, the area of islands and beaches have significantly reduced.

The left eastern bank of the Volga river, where Samara is located, is relatively low, its absolute marks lie in the range of 40-50 $\mathrm{m}$. Alluvial and deluvial deposits of the quaternary system are the most widely spread in the territory of Samara in the upper part of the section. Lithologically they are from loam soil, sandy loam, sand, and clay.

The deluvial deposits on the valley slopes lie above the rear rim of the second terrace above the floodplain of the Volga, Chapaevka and Chagra rivers and so on at an altitude range of 60-100 m. These include sloping shelves accumulated by loam soil, clay and sand with granitic subsoil and gravel of carbonate rocks. The thickness of the deluvial deposits varies from 1 to $16 \mathrm{~m}[4,14]$. 
The alluvial deposits make the first and second terraces above the floodplain of the Volga, Samara, Chapaevka and Usa rivers, and so on. They occupy the largest area on the left bank of the Volga. The upper part of the section is represented by clay, loam soil and sandy loam with sand layers, the lower part is composed of sands including the coarse sand and gravel. The thickness in the Volga River valley reaches 45-52 $\mathrm{m}$ [15].

While working on the urban development master plan on the Samara territory, four sites with subsiding soil expansion were identified: the first and second terraces above the floodplain of the Samara river (the Bezymyanka district), the third terrace above the floodplain of the Volga river and the Samara watershed slope $[4,16]$.

\section{Discussion}

Two types of ground were identified. In the first type area, the subsidence does not exceed $5 \mathrm{~cm}$. In the second type area, the subsidence while soaking under the residential load is 5 $20 \mathrm{~cm}$.

The circulating water in the city is represented by the following aquifers. The waterbearing complex of the modern alluvial deposits refers to floodplain deposits of Volga and Samara. The aquifer has been studied by numerous wells and boreholes. The water-bearing materials are fine-grained sand, loam soil and sandy loam. The filtration coefficient changes from $1.01 \mathrm{~m} /$ day to $4.39 \mathrm{~m} /$ day. The water-bearing material thickness ranges from 2.0 to $11.0 \mathrm{~m}$. The aquifer is free-flow and it has a slope in the direction of the rivers. The depth of alluvial water is directly dependent on the terrain relief and varies from 1.0 to $5.0 \mathrm{~m}$. The groundwater chemical composition is mainly bicarbonate, often with a high content of sulfates and chlorides and magnesium-calcium. Water is polluted with nitrates. The recharge occurs with infiltration of precipitation and inflow from rivers. The groundwater of quaternary sediments is fresh with mineralization of $0.3-0.7 \mathrm{~g} / 1$, sometimes even more. Their chemical composition is sulfate-bicarbonate, calcium-sodium, sometimes they are mixed. The water is suitable for drinking and household purposes and is used by the local population by means of boreholes and wells. The water abundance of the aquifer depends on the lithology. The aquifer recharge occurs due to the infiltration of precipitation and inflow from the aquifer of the Khazar terrace $[4,17]$.

The middle quaternary alluvial aquifer. Its deposits are widespread. They make the second terrace above the floodplain of the Volga, Samara, Chapaevka and Usa rivers. The water-bearing materials are loam soils with sand and clay bands at the bottom of the section with sand and gravel bands. They lie at a depth of 5.0 to $27.0 \mathrm{~m}$. The thickness of the waterbearing layer varies from 2.0 to $56.0 \mathrm{~m}$. The groundwater, free-flow, pressure in some places. The filtration coefficients calculated according to the pumping tests range from 0.4 to $3.5 \mathrm{~m} /$ day. The considered aquifer forms a single hydraulic system with the aquifer of modern floodplain and the upper quaternary deposits. The recharge occurs due to the infiltration of precipitation and inflow from other aquifers. The water is widely used for domestic water supply, especially on the left bank of Volga river [16, 18].

As a result of more than 20 years of engineering and geological studies of the Samara territories the subsiding soils were found in Leninsky, Oktyabrsky, Kirovsky and Krasnoglinsky districts, both on the terraces of the Volga and Samara rivers, and on the slope. It should be noted that the subsiding loess soils are very widespread $[4,18]$.

The area of study was located on the second terrace above the floodplain of the Samara river, the part of the territory was occupied by the subsiding soil, with mainly solid and semi-solid loam soils and hard-plastic sandy loam texture. The exposed lower limit of subsiding strata occurrence varies from $3.0 \mathrm{~m}$ to $12.5 \mathrm{~m}$. The most widespread soils are those which at a pressure of $\mathrm{P}=0.2-0.3 \mathrm{MPa}$ is $\varepsilon_{\mathrm{sl}}=0,01-0,022$. (The average magnitude of 
relative subsidence $\varepsilon_{\mathrm{sl}}=0,01$; the initial subsiding pressure is $95-220 \mathrm{kPa}$ ). The first type subsiding soil conditions are mainly spread.

Locally, there are areas with the subsiding soils that have relative subsidence under loads of $\mathrm{P}=0.2-0.3 \mathrm{MPa}$ equal to $\varepsilon_{\mathrm{sl}}=0.010-0.044$; the initial subsidence pressure ranges from $70 \mathrm{kPa}$ to $210 \mathrm{kPa}$. Based on the relative subsidence, according to GOST 25100-2011, these soils are classified as extremely subsiding. The subsiding soil conditions refer to the second type (Table 1, Figure 2).

Table 1. Magnitude of relative subsidence and initial subsiding pressure

\begin{tabular}{|c|c|c|c|c|}
\hline \multirow{2}{*}{ Depth, $\mathrm{m}$} & \multicolumn{3}{|c|}{ Relative subsidence under pressure, $\mathrm{MPa}$} & \multirow{2}{*}{$\begin{array}{c}\text { Initial subsiding } \\
\text { pressure, } \mathrm{P}_{\mathrm{sl}}, \mathrm{kPa}\end{array}$} \\
\cline { 2 - 4 } & 0.1 & 0.2 & 0.3 & 140 \\
\hline $3.0-3.2$ & - & 0.014 & - & 120 \\
\hline $5.0-5.2$ & 0.008 & 0.015 & 0.042 & 150 \\
\hline $7.0-7.2$ & 0.006 & 0.013 & 0.029 & 170 \\
\hline $9.0-9.2$ & - & 0.012 & - & 70 \\
\hline $12.0-12.2$ & 0.007 & 0.009 & 0.021 & 140 \\
\hline $14.8-15.0$ & - & 0.014 & - & \\
\hline
\end{tabular}

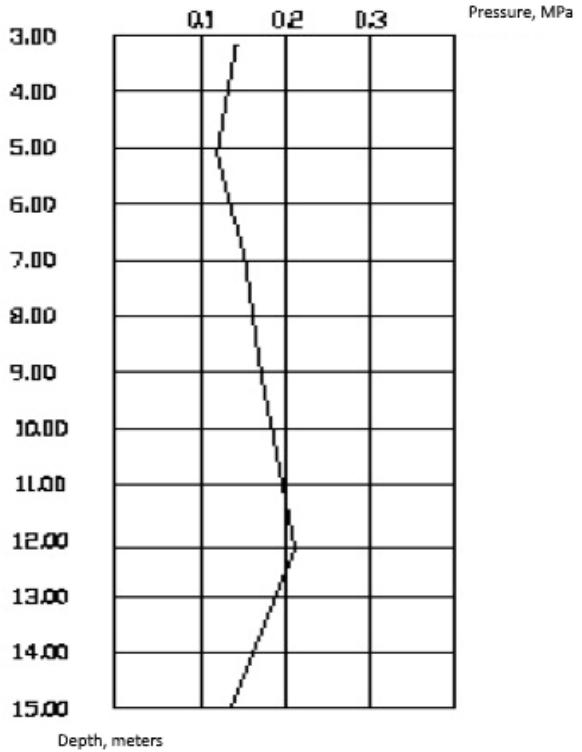

Fig. 2. Alteration of the initial subsiding pressure with depth

The study found that under the influence of long-term groundwater level increase, the physical and mechanical properties of subsiding loess soils have changed: the flow rate of soil has changed from $<0-0.25$ to $0.25-0.50$; the porosity of the soil has changed from $39.9 \%-50.9 \%$ to $40 \%-31 \%$. Therefore, according to the classification of the soils in terms of flow index, their properties have changed from solid to low-plasticity. The natural moisture of subsiding sandy loam and loam soils was 4-25\%; later it was $12-49 \%$.

During the construction and operation process, an uneven subsidence of the Earth's surface is possible after the surface relief damage, its waterproofing removal, when watering the subsiding soil with precipitation or technogenic watering, which leads to uneven deformations of the structure. 


\section{Conclusions}

Thus, over the last decade in the city due to the increased level of groundwater in the area of a large water reservoir on the Volga river, there is an increase in the lower limit of subsiding strata distribution and reduction of its thickness. For new construction, this process has a positive effect, and it is negative for existing buildings and structures due to the physical and mechanical properties deterioration of soils by increasing their moisture.

It is necessary to take into account the subsiding loess soil modification when planning how to use the city's territory in today's growing density and a number of storeys in urban development.

Thus, it is shown that the widespread occurrence of the loess soils in the large lowland reservoir area can lead to the surface subsidence. On the territory of large industrial cities, it can lead to catastrophe, accidents with the release of chemically and biologically hazardous substances. To liquidate these consequences, significant financial, logistical and human resources are required that could be used for the development of the economy and social sphere. Therefore, the development and implementation of effective measures to minimize the inevitable damage from natural disasters, and the concentration of efforts on preventing technogenic and natural- technogenic disasters become the top priority.

That is why, one of the basic principles of sustainable development in Russia should be the advancing adoption of effective measures to prevent deterioration of the environment, the prevention of environmental and technogenic disasters.

\section{References}

1. A.N. Ryazantsev, A.L. Lysenko, N. Rybalskaya, and others, Environmental safety in the construction industry (1999)

2. E.S. Rozhdestvenskaya, Urban Construction and Architecture 1 (9), 25-30 (2013). DOI: $10.17673 /$ Vestnik.2013.01.5

3. E.M. Galperin, Urban Construction and Architecture 3 (24), 31-37 (2016). DOI: 10.17673/Vestnik.2016.03.5

4. D.I. Vasilieva, M.N. Baranova, O.M. Kakutina, I.P. Shimanchik, Geology and soil cover of the Samara territory (Publ. SMMI, Samara, 2011)

5. E.M. Sergeeva, A.K. Larionov, N.N. Komissarova, The loess materials in USSR. Engineering and geological characteristics and problems of rational use, (1996)

6. E.V. Pantyushina, Polzunovsky Vestnik 1, 127-130 (2011)

7. P. Antoine, Revue Française de Géotechnique 99, 3-21 (2002).

8. E. M. Sergeev, V.S. Bykova, N. N. Komissarova, The USSR loess materials. Regional features, Vol. 2. (1986)

9. G.I. Shvetsov, I.V. Noskov, A.D. Slobodyan, G.S. Goskova, Bases and foundations: the reference book (1991)

10. B.J. Andersen, H.W. Borns, The Ice age of World (Scandinavian University Press, Oslo, 1997).

11. N.I. Krieger, The loess. The formation of subsidence properties (1986)

12. G.I. Shvetsov, The loess rocks in Western Siberia and methods for bases and foundation installation (2000)

13. T.V. Dormidontova, A.V. Maltsev, Design and construction in Siberia 2, 25-26 (2010) 
14. O.M. Kakutina, Traditions and innovations in construction and architecture. Construction, 252-257 (2015)

15. A.V. Maltsev, V.N. Yakovlev, E.V. Timchenko, N.V. Tregub, Traditions and innovations in construction and architecture. Construction, 287-294 (2015)

16. M.N. Baranova, D.I. Vasilyeva, Traditions and innovations in construction and architecture. Construction, 189-193 (2016)

17. A.V. Maltsev, Y.A. Chizhkova, I.A. Atlashova, Traditions and innovations in construction and architecture. Construction, 211-215 (2016)

18. V.V. Voronin, A.G. Vlasov, D.I. Vasilieva, E.S. Most, Ecology of the urbanized territories, 4, 76-86 (2013) 